\title{
ASO Visual Abstract: Treatment Switch for Poor Responders with Locally Advanced Gastric Cancer After Neoadjuvant Chemotherapy
}

\section{Zining Liu, MD, Yinkui Wang, MD, Fei Shan, MD, Xiangji Ying, MPH, Yan Zhang, MPH,} Shuangxi Li, MD, Yongning Jia, MD, Rulin Miao, MD, Kan Xue, MD, Zhemin Li, MD, Ziyu Li, MD, PhD, and Jiafu Ji, MD, PhD

Key Laboratory of Carcinogenesis and Translational Research, (Ministry of Education/Beijing), Gastrointestinal Cancer Center, Peking University Cancer Hospital \& Institute, Beijing, China

This study investigated the efficacy of using non-crossresistant postoperative regimens for patients with locally advanced gastric cancer (LAGC) who received neoadjuvant chemotherapy with a poor pathologic response (h ttps://doi.org/10.1245/s10434-021-10087-x). Neither a survival benefit nor a significantly improved tolerability was found for the patients with treatment switch strategies.

Zining Liu and Yinkui Wang have contributed equally.

(C) The Author(s) 2021

Published Online: 13 September 2021

Z. Li, MD, PhD

e-mail: ziyu_li@hsc.pku.edu.cn

J. Ji, MD, PhD

e-mail: jijiafu@hsc.pku.edu.cn 


\section{Treatment Switch in Poor-Responders With Locally Advanced Gastric Cancer After Neoadjuvant Chemotherapy}

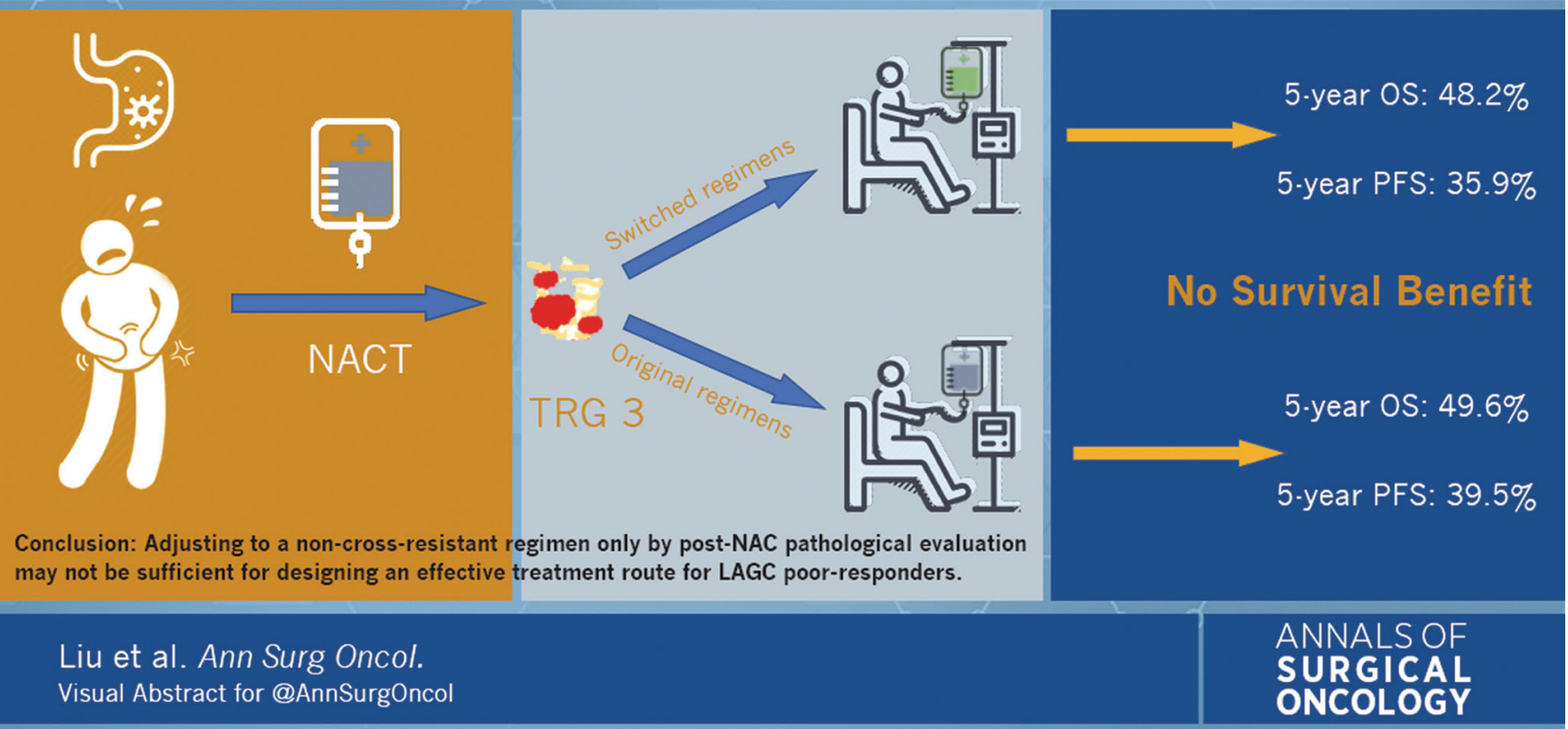

FUNDING This work was funded by Beijing Municipal Health Commission (DFL20181103, ZYLX201701).

DISCLOSURE There are no conflicts of interest.

OPEN ACCESS This article is licensed under a Creative Commons Attribution 4.0 International License, which permits use, sharing, adaptation, distribution and reproduction in any medium or format, as long as you give appropriate credit to the original author(s) and the source, provide a link to the Creative Commons licence, and indicate if changes were made. The images or other third party material in this article are included in the article's Creative Commons licence, unless indicated otherwise in a credit line to the material. If material is not included in the article's Creative Commons licence and your intended use is not permitted by statutory regulation or exceeds the permitted use, you will need to obtain permission directly from the copyright holder. To view a copy of this licence, visit http://creativecommons. org/licenses/by/4.0/.

Publisher's Note Springer Nature remains neutral with regard to jurisdictional claims in published maps and institutional affiliations. 